\title{
BRD9 EXPRESSION, ALTERATION, SURVIVAL AND PATHWAY ANALYSIS IN 11 INDEPENDENT PROSTATE CANCER COHORTS.
}

\author{
Nafisa Barma ${ }^{1}$, Timothy C Stone ${ }^{1}$, Lina Maria Carmona Echeverria ${ }^{2}$, Susan Heavey ${ }^{1}$. \\ 1 Division of Surgery and Interventional Sciences, UCL \\ 2 Princess Alexandra Hospital NHS Trust, Harlow
}

\begin{abstract}
Background and aims: Despite recent advances in advanced prostate cancer treatments, there are no clinically useful biomarkers or treatments for men with such cancers. Targeted therapies have shown promise, but there remain fewer actionable targets in prostate cancer than in other cancers. This work aims to characterize BRD9, currently understudied in prostate cancer, and investigate its co-expression with other genes to assess its potential as a biomarker and therapeutic target in human prostate cancer.
\end{abstract}

Materials and methods: Omics data from a total of 2053 prostate cancer patients across 11 independent datasets were accessed via Cancertool and cBioPortal. mRNA expression and co-expression, mutations, amplifications, and deletions were assessed with respect to key clinical parameters including survival, Gleason grade, stage, progression and treatment. Network and pathway analysis was carried out using Genemania, and heatmaps were constructed using Morpheus.

Results: BRD9 is overexpressed in prostate cancer patients, especially those with metastatic disease. BRD9 expression did not differ in patients treated with second generation antiandrogens versus those who were not. BRD9 is co-expressed with many genes in the SWI/SNF and BET complexes, as well as those in common signaling pathways in prostate cancer.

Summary and conclusions: BRD9 has potential as a diagnostic and prognostic biomarker in prostate cancer. BRD9 also shows promise as a therapeutic target, particularly in advanced prostate cancer, and as a co-target alongside other genes in the SWI/SNF and BET 
complexes, and those in common prostate cancer signalling pathways. These promising results highlight the need for wider experimental inhibition and co-targeted inhibition of BRD9 in vitro and in vivo, to build on the limited inhibition data available. 


\section{INTRODUCTION}

\section{Prostate cancer and its biomarkers}

Prostate Cancer (PCa) is the second most common cancer in men and the most commonly diagnosed in the UK, representing $7.1 \%$ of new cancers and $3.8 \%$ of cancer deaths worldwide [1-4].

Prostate-Specific Antigen (PSA) is a protein typically produced in the prostate and used as a biomarker to prompt further investigation (e.g. biopsy) for PCa and its recurrence)[5]. PSA does not provide any information about the aggressivity and stage of any potential cancer and testing is often associated with overdiagnosis and overtreatment, with a recent meta-analysis finding that screening did not impact overall mortality despite men who were screened having a higher incidence of $\mathrm{PCa}$ [6]. There are efforts to improve the diagnosis and discovery of $\mathrm{dx}$ biomarkers including the United States Food and Drug Administration (FDA)-approved Progensa assay (PCA3 (prostate cancer gene 3) and PSA) and STHLM3 (Stockholm-3) which is currently being validated [7-9]. However, these are imperfect and more sensitive and specific biomarkers are needed both for detecting PCa and driving treatment [10].

\section{Current therapies for PCa}

Though PCa survival is relatively high ( $85 \%$ five-year survival), this is much reduced $(50 \%)$ for stage four PCa [11]. Treatments are often invasive with side effects for radical prostatectomy (surgical removal of the prostate) and radiotherapy, including urinary incontinence and erectile dysfunction $[12,13]$. Therapies for PCa range from hormonal therapies (including androgen deprivation therapy (ADT)) to chemotherapy and recentlyapproved targeted therapies. Targeted therapies aim to inhibit specific proteins and are a promising future area of therapeutics for PCa, with the recent FDA approval of the poly-ADP ribose polymerase inhibitors (PARPi) Olaparib and Rucaparib for metastatic castrationresistant prostate cancer ( $\mathrm{mCRPC})[14]$.

With poor outcomes for patients with advanced stage cancer and the development of resistance to existing therapies, BRD9 may have utility along the PCa clinical pathway as a biomarker, and a therapeutic target. New targeted therapies with less toxic and life-altering effects would be of great benefit in treating patients with PCa. 


\section{SWI/SNF and BET complexes}

BRD9 is a genetic subunit of the non-canonical barrier-to-autointegration factor (ncBAF), also termed GBAF. This is one of the subunits composing the Switch/Sucrose NonFermentable (SWI/SNF) complex along with canonical barrier-to-autointegration factor (cBAF) and Polybromo-barrier-to-autointegration factor (PBAF). These complexes are involved in chromatin remodelling and cancer, containing both oncogenes and tumour suppressor genes [15]. Similarly, the Bromodomain and extra-terminal domain (BET) complex is involved in regulating transcription by RNA polymerase II [16]. This represents a possible therapeutic target in PCa with the selective small-molecule BET inhibitors JQ1 and I-BET preventing growth of androgen receptor (AR) positive castrate-resistant prostate cancer (CRPC) cell lines [17].

\section{Common signaling pathways in PCa}

Pathways involved in driving PCa proliferation involve the JAK-STAT (janus kinase; signal transducer and activator of transcription), MAPK (mitogen-activated protein kinase) and PI3K-AKT-mTOR (phosphoinositide 3-kinase; Protein Kinase B; mammalian target of rapamycin) pathways.

The JAK-STAT pathway is regulated by SOCS (suppressor of cytokine signaling) genes and is involved in regulation of "cell growth, differentiation, proliferation, invasion, survival, and inflammation" [18]. Its persistent activation in PCa can result in progression, rendering it a worthwhile therapeutic target, with one study finding STAT5A/B gene amplification and increased protein expression in $\mathrm{PCa}$, and to a greater extent in higher grade, castrationresistant and metastatic disease [18,19]. The MAPK pathway is also involved in cell regulation and represents a possible therapeutic target in $\mathrm{PCa}$, with one study finding patients with increased nuclear MAPK protein expression more likely to develop CRPC, earlier biochemical relapse and reduced survival [20,21]. Another study found $32 \%$ of patients with mCRPC have frequent amplifications in MAPK pathway-involved genes, and that this pathway is a promising target for mCRPC, with extracellular receptor kinase 1 (ERK1) inhibitor trametinib (currently approved for melanoma) being investigated for $\mathrm{MCRPC}$ in a phase II trial [22]. PI3K-AKT-mTOR is another often-dysregulated signaling pathway, especially in CRPC [23]. Though no drugs targeting this pathway have been approved in $\mathrm{PCa}$, the AKT-inhibitor ipatasertib performed well in combination with abiraterone in a phase Ib/II study, and the IPATential150 phase III trial is underway [24,25]. Initial data shows a 
higher radiographic progression-free survival in the ipatasertib compared to the control group (18.5 months vs 16.5 months) though it is too early for overall survival (OS) data and conclusions to be drawn [26]. Transmembrane protease, serine 2-erythroblast transformationspecific (TMPRSS2-ETS) genetic fusion is a molecular subtype (ETS-related gene (ERG) positive) of $\mathrm{PCa}$ associated with cancer invasiveness found in 50\% of PCa tumours [27,28]. Agents such as the small-molecule selective ERG inhibitor ERGi-USU (1-[2-Thiazolylazo]2-naphthol) are being developed to target this fusion [29].

These pathways may represent opportunities for co-targeting with BRD9 as well as being targets themselves.

\section{BRD9 and PCa}

BRD9 has not been well studied in prostate cancer to date with one paper published in December 2020 [30]. This paper showed that BRD9 inhibition and knockdown have overlapping effects, reducing AR-positive cell line growth both in vivo and in vitro. The authors also found that BRD9 interacts with the AR in PCa cell lines, even those resistant to androgen deprivation and inhibition. They also provided cell-line evidence that BRD9 and the BET complex associate with each other and interact given they have overlapping transcriptional targets.

Despite being the first paper on BRD9 in PCa, the authors did not begin with an unbiased characterisation of this gene in human PCa using extensive existing publicly available data. Instead they focussed almost exclusively on CRPC (developed by 10-20\% PCa patients within 5 years), and worked with cell lines [31]: Much remains to be answered regarding BRD9's behaviour across the clinical pathway. However, the authors' findings were encouraging, warranting further investigation which could lead to clinical trials if future results continue to have promise.

Here we set out to determine whether BRD9 represents a potential biomarker, monotherapeutic target and co-target alongside other targeted therapies in PCa. 


\section{MATERIALS AND METHODS}

\section{Cancertool, cBioPortal and Genemania}

Cancertool was used to access BRD9 messenger ribonucleic acid (mRNA) expression in PCa cohorts as well as gene mRNA correlations in PCa. It is a publicly available interface that generates graphical visualisations of data, performs some statistical analyses and allows users to download raw data for processing and analysis [32].

The cBioPortal for Cancer Genomics was also used to access PCa cohort data. This platform integrates various genomic data, allowing users to investigate, view and download data relating to gene expression, mutation data (for some cohorts) and clinical attributes $[33,34]$.

Genemania performs network analyses between inputted genes and presents relationships as a colour-coded network [35].

The following cohorts (cancer omics datasets) were accessed via Cancertool and cBioPortal (Table 1). 


\begin{tabular}{|c|c|c|c|c|c|c|c|c|c|c|c|}
\hline & TCGA [36] & Glinsky [37] & Grasso [38] & Taylor [39] & Varambally [40] & $\begin{array}{l}\text { Gerhauser } \\
\text { [41] }\end{array}$ & Barbieri [42] & $\operatorname{Ren}[43]$ & Abida [44] & Dan [45] & Kumar [46] \\
\hline $\begin{array}{l}\text { Cancertool } \\
\text { name }\end{array}$ & TCGA & Glinsky & Grasso & Taylor & Varambally & $\mathrm{N} / \mathrm{A}$ & N/A & N/A & N/A & N/A & N/A \\
\hline $\begin{array}{l}\text { cBioPortal } \\
\text { name }\end{array}$ & $\begin{array}{l}\text { TCGA Firehose } \\
\text { Legacy }\end{array}$ & $\mathrm{N} / \mathrm{A}$ & $\begin{array}{l}\text { Metastatic } \\
\text { Prostate } \\
\text { Adenocarcinoma } \\
\text { (MCTP, Nature } \\
\text { 2012) }\end{array}$ & $\begin{array}{l}\text { Prostate } \\
\text { Adenocarcino } \\
\text { ma (MSKCC, } \\
\text { Cancer Cell } \\
\text { 2010) }\end{array}$ & $\mathrm{N} / \mathrm{A}$ & $\begin{array}{l}\text { Prostate } \\
\text { Cancer } \\
\text { (DKFZ, } \\
\text { Cancer Cell } \\
\text { 2018) }\end{array}$ & $\begin{array}{l}\text { Prostate } \\
\text { Adenocarcino } \\
\text { ma } \\
\text { (Broad/Cornell } \\
\text { Nat Genet } \\
\text { 2012) }\end{array}$ & $\begin{array}{l}\text { Prostate } \\
\text { Adenocarcinom } \\
\text { a (SMMU, Eur } \\
\text { Urol 2017) }\end{array}$ & $\begin{array}{l}\text { Metastatic } \\
\text { Prostate } \\
\text { Adenocarcinoma } \\
\text { (SU2C/PCF } \\
\text { Dream Team, } \\
\text { PNAS 2019) }\end{array}$ & $\begin{array}{l}\text { Metastatic } \\
\text { Prostate Cancer } \\
\text { SU2C/PCF Dream } \\
\text { Team, Cell 2015) }\end{array}$ & $\begin{array}{l}\text { Prostate } \\
\text { Adenocarcinoma } \\
\text { (Fred Hutchinson } \\
\text { CRC, Nat Med } \\
\text { 2016) }\end{array}$ \\
\hline $\begin{array}{l}\text { Number of } \\
\text { patients (N) }\end{array}$ & 499 & 79 & 61 & 218 & 13 & 251 & 112 & 65 & 429 & 150 & 176 \\
\hline Cancer type & $\begin{array}{l}\text { Primary prostate } \\
\text { adenocarcinoma }\end{array}$ & $\begin{array}{l}\text { Recurrent ( } n=37) \\
\text { and nonrecurrent } \\
(n=42) \text { disease }\end{array}$ & $\begin{array}{l}\text { Heavily penetrated } \\
\text { CRPC }(n=50) \text {, high } \\
\text { grade localised } \\
\text { PCa }(n=11)\end{array}$ & 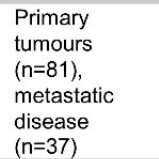 & $\begin{array}{l}\text { Primary tumours } \\
(n=7) \text {, metastatic } \\
\text { disease }(n=6)\end{array}$ & $\begin{array}{l}\text { Primary } \\
\text { prostate } \\
\text { adenocarcino } \\
\text { ma }\end{array}$ & $\begin{array}{l}\text { Prostate } \\
\text { adenocarcino } \\
\text { ma }\end{array}$ & $\begin{array}{l}\text { Prostate } \\
\text { adenocarcinoma }\end{array}$ & Metastatic CRPC & Metastatic CRPC & $\begin{array}{l}\text { Primary and } \\
\text { metastatic }- \\
\text { mCRPC }(n=63)\end{array}$ \\
\hline $\begin{array}{l}\text { Treatment } \\
\text { (prior to } \\
\text { specimen } \\
\text { collection) }\end{array}$ & Naîve & $\begin{array}{l}\text { Undergoing } \\
\text { routine treatment }\end{array}$ & $\begin{array}{l}\text { Prostatectomy, } \\
\text { chemotherapy, } \\
\text { hormone therapy, } \\
\text { radiotherapy, } \\
\text { palliative } \\
\text { radiotherapy. } \\
\text { Localised cancers } \\
\text { were treatment } \\
\text { naïve. }\end{array}$ & No information & No information & $\begin{array}{l}\text { Treatment } \\
\text { naïve (except } \\
\text { for two } \\
\text { patients } \\
\text { receiving } \\
\text { neoadjuvant } \\
\text { hormone } \\
\text { therapy) }\end{array}$ & $\begin{array}{l}\text { Treatment- } \\
\text { naïve }\end{array}$ & Treatment-naïve & $\begin{array}{l}\text { Standard of care } \\
\text { (including second } \\
\text { generation } \\
\text { antiandrogens)/enr } \\
\text { olled in a clinical } \\
\text { trial (e.g. targeted } \\
\text { therapy) }\end{array}$ & $\begin{array}{l}\text { Various - second } \\
\text { generation } \\
\text { antiandrogens, } \\
\text { clinical trial, } \\
\text { taxane } \\
\text { chemotherapy }\end{array}$ & $\begin{array}{l}\text { ADT followed by } \\
\text { second-generation } \\
\text { antiandrogens } \\
\text { (following disease } \\
\text { progression) and } \\
\text { docetaxel } \\
\text { chemotherapy }\end{array}$ \\
\hline $\begin{array}{l}\text { Method of } \\
\text { sample } \\
\text { collection }\end{array}$ & $\begin{array}{l}\text { Radical } \\
\text { prostatectomy }\end{array}$ & $\begin{array}{l}\text { During } \\
\text { therapeutic/diagn } \\
\text { ostic procedures }\end{array}$ & $\begin{array}{l}\text { Rapid autopsy } \\
\text { (CRPC) and } \\
\text { radical } \\
\text { prostatectomy } \\
\text { (localised) }\end{array}$ & $\begin{array}{l}\text { Radical } \\
\text { prostatectomy }\end{array}$ & $\begin{array}{l}\text { Radical } \\
\text { prostatectomy } \\
\text { and rapid } \\
\text { autopsy }\end{array}$ & $\begin{array}{l}\text { Radical } \\
\text { prostatectomy }\end{array}$ & $\begin{array}{l}\text { Radical } \\
\text { prostatectomy }\end{array}$ & $\begin{array}{l}\text { Radical } \\
\text { prostatectomy }\end{array}$ & $\begin{array}{l}\text { Radiographic- } \\
\text { guided biopsy }\end{array}$ & $\begin{array}{l}\text { Radiographic- } \\
\text { guided biopsy }\end{array}$ & Rapid autopsy \\
\hline \multirow[t]{5}{*}{$\begin{array}{l}\text { Gleason } \\
\text { grade }\end{array}$} & $\begin{array}{l}\text { 5: - } \\
\text { 6: } 45(9 \%)\end{array}$ & $\begin{array}{l}\text { 5: - } \\
\text { 6: } 15(19 \%)\end{array}$ & $\begin{array}{l}\text { 5:- } \\
\text { 6:- }\end{array}$ & $\begin{array}{l}\text { 5: } 2(1 \%) \\
6: 101(47 \%)\end{array}$ & - & $\begin{array}{l}\text { 5: - } \\
\text { 6: } 13(11 \%)\end{array}$ & $\begin{array}{l}\text { 5: - } \\
\text { 6: } 4(20 \%)\end{array}$ & $\begin{array}{l}\text { 5:- } \\
\text { 6: } 5(8 \%)\end{array}$ & $\begin{array}{l}\text { 5: - } \\
\text { 6: } 15(9 \%)\end{array}$ & $\begin{array}{l}- \\
-\end{array}$ & - \\
\hline & 7: $244(50 \%)$ & 7: $45(57 \%)$ & $7: 2(18 \%)$ & 7: $77(36 \%)$ & - & $7: 86(74 \%)$ & $\begin{array}{l}\text { 7: } 13(65 \%) \\
7.5: 1(5 \%)\end{array}$ & $7: 37(57 \%)$ & 7: $49(29 \%)$ & - & - \\
\hline & 8: $63(13 \%)$ & 8: $10(13 \%)$ & 8: $4(36 \%)$ & 8: $19(9 \%)$ & - & 8:1(1\%) & $8: 2(10 \%)$ & 8: $9(14 \%)$ & $8: 23(14 \%)$ & - & - \\
\hline & 9: $135(27 \%)$ & 9: $9(11 \%)$ & 9: $5(46 \%)$ & 9: $15(7 \%)$ & - & 9: $15(13 \%)$ & 9:- & $9: 12(18 \%)$ & 9: $67(40 \%)$ & - & - \\
\hline & $\begin{array}{l}\text { 10: } 4(1 \%) \\
11:-\end{array}$ & 10: - & $\begin{array}{l}\text { 10: - } \\
\text { 11: }\end{array}$ & $\begin{array}{l}\text { 10: } \\
\text { 11:- }\end{array}$ & - & $\begin{array}{l}\text { 10: } 1(1 \% \\
\text { 11: }-\end{array}$ & $\begin{array}{l}\text { 10: }- \\
11:-\end{array}$ & $\begin{array}{l}\text { 10: } 2(3 \%) \\
\text { 11:- }\end{array}$ & $\begin{array}{l}\text { 10: } 13(8 \%) \\
11: 1(1 \%)\end{array}$ & - & - \\
\hline $\begin{array}{l}\text { Total patients } \\
\text { (n) for whom } \\
\text { a Gleason } \\
\text { grade was } \\
\text { available }\end{array}$ & $491(100 \%)$ & $79(100 \%)$ & $\begin{array}{l}11(100 \%) \\
\text { (High grade } \\
\text { localised PCas } \\
\text { only) }\end{array}$ & $214(100 \%)$ & $\begin{array}{l}\text { No data } \\
\text { available }\end{array}$ & $116(100 \%)$ & $20(100 \%)$ & $65(100 \%)$ & $168(101 \%)$ & No data available & No data available \\
\hline
\end{tabular}

Table 1: Characteristics of human prostate cancer omics datasets investigated.

Table summarising characteristics of publicly available cancer omics datasets and their patients. For each clinical attribute investigated, there was not necessarily data for each patient in the cohort. 


\section{Clinical correlations and co-expression analysis}

Clinical correlations were investigated by downloading raw data from Cancertool and cBioPortal and processing the data using Microsoft Excel. Following this, data were graphed, and statistical analyses carried out using GraphPad Prism version 9.1.0.

Co-expression between BRD9 and genes involved in signalling pathways and complexes of interest were investigated using Genemania and Cancertool. Spearman's rank-order correlation coefficient (R) and its statistical significance were calculated in Cancertool. Correlation coefficient data was then processed using Microsoft Excel and heatmaps were created using Morpheus to visually represent the correlation between BRD9 expression and expression of other related genes of interest [47]. Once generated, the heatmaps were examined and $p$ values were manually indicated by adding ' $*$ ' to any pixel whose correlation was significant $(\alpha=0.05)$.

\section{Comparing continuous data}

Before comparisons were performed, data were graphed and tested for normality using Shapiro-Wilk and Kolmogorov-Smirnov tests. All data were unpaired. When comparing two groups, normally distributed data were analysed using Welch's t-test, as group standard deviations differed. Non-normally distributed data were analysed using a Mann-Whitney U test. Where more than two groups were to be compared, normally distributed data were analysed using the Brown-Forsythe and Welch's analysis of variance (ANOVA) test as group standard deviations differed. Dunnett's T3 test was then performed as a post-hoc multiple comparisons test. Non-normally distributed data were analysed using the Kruskal-Wallis test. Dunn's test was then performed as a post-hoc multiple comparisons test.

Following statistical analysis, data were graphed using violin plots, as these better illustrate data distribution and density than bar graphs and box and whisker plots [48].

\section{Correlations}

Spearman's R correlations could be classified very weak, weak, moderate, strong or very strong (Table 2) [49]. 


\begin{tabular}{|l|l|l|}
\hline & Spearman's R (positive) & Spearman's R (negative) \\
\hline Very weak & $0-0.19$ & $0--0.19$ \\
\hline Weak & $0.2-0.39$ & $-0.2--0.39$ \\
\hline Moderate & $0.4-0.59$ & $-0.4--0.59$ \\
\hline Strong & $0.6-0.79$ & $-0.6--0.79$ \\
\hline Very strong & $0.8-1$ & $-0.8--1$ \\
\hline
\end{tabular}

Table 2: Classification of correlation strength.

Table summarising correlation strength.

\section{Survival analysis}

Disease-free Survival (DFS) was illustrated using Kaplan-Meier survival curves. Patients were grouped by quartile expression of BRD9. A Mantel-Cox test was performed to compare the differences between curves and a cox regression model was used to calculate hazard ratio (HR) between the first and fourth quartiles.

\section{Comparing mutation distribution}

Where mutation data was available, this was graphed using stacked bar charts. As categorical variables investigated had small sample sizes and expected frequencies $<1$ for some cells, Fisher's exact test was required to analyse mutation distribution. This test was implemented in R. In some instances, modified estimates of the p-value were necessary as certain tables were too computationally intensive to calculate. The approximation was calculated via a Monte Carlo simulation (number of samples $=1,000,000$ ). In every instance, the $p$-values indicated that the data were considerably below the threshold for significance $\left(\mathrm{p}<10^{-5}\right)$. 


\section{RESULTS}

\section{BRD9 has potential as a diagnostic and prognostic biomarker in PCa.}

BRD9 is overexpressed in human prostate tumour tissue, playing a role as a diagnostic biomarker. It may also be overexpressed in more aggressive PCa and this overexpression may correlate with reduced survival in patients. Comparison of BRD9 expression in the Grasso cohort revealed that BRD9 is overexpressed in PCa patients $(p=0.0462)$ (Figure 1a). In the Taylor cohort, there was no significant difference in BRD9 expression $(p=0.6726)$, however this was positively skewed (Figure 1b). The Varambally cohort also showed greater BRD9 expression in $\mathrm{PCa}(\mathrm{p}=0.0053)$ compared to benign samples from the same prostate (Figure 1c). Regarding Gleason grade and BRD9 mRNA expression, using Gleason grade 6 as a baseline there was no significant change in BRD9 expression level as Gleason grade increased in the Glinsky cohort $(\alpha=0.05)$ (Figure 1d). In the Taylor cohort, there was only a significant change (decrease) in BRD9 expression at Gleason grade $8(\mathrm{p}=0.0100)$ (Figure 1e). In the TCGA cohort, there was no significant difference between Gleason grade and BRD9 expression $(\alpha=0.05)$ (Figure 1f). BRD9 mutations were more prevalent in patients with higher graded disease $(\mathrm{p}<0.0001)$ (Figure 1g). In terms of BRD9 expression in normal prostate, primary, and metastatic $\mathrm{PCa}$, in the Grasso cohort there was no significant difference $(\mathrm{p}=0.9268)$ in BRD9 expression between normal prostate and primary PCa, however there was a significant increase in BRD9 expression in the metastatic PCa group both when compared to benign prostate $(\mathrm{p}-0.0025)$ and primary prostate cancer $(\mathrm{p}=0.0016)$ groups

(Figure 1h). Similarly in the Taylor cohort, there was only a significant increase in BRD9 expression between the normal prostate and metastatic $(\mathrm{p}=0.0152)$, and primary and metastatic groups $(\mathrm{p}=0.0017)$ (Figure 1i). The Varambally cohort only showed a significant change in BRD9 expression between the normal and metastatic groups $(p=0.0270)$ (Figure 1j). In the Glinsky cohort, patients with higher BRD9 expression had significantly higher DFS ( $\mathrm{p}=0.0190)$ (Figure 1k). In the Taylor cohort, there was no significant difference $(\mathrm{p}=0.8532)$ in DFS between patients with the lowest and highest BRD9 expression (Figure 11). In the TCGA cohort, patients with higher BRD9 levels had significantly lower DFS than those with lower levels $(\mathrm{p}=0.0015)($ Figure 1 m). 
A

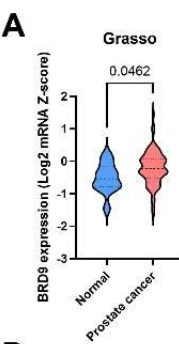

D

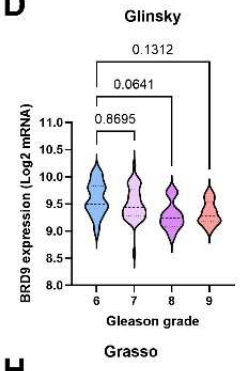

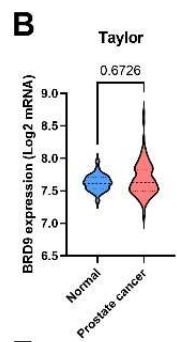

E

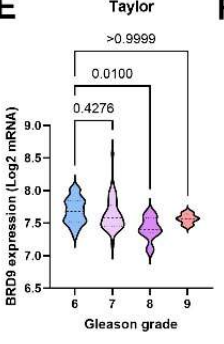

I
C varambally

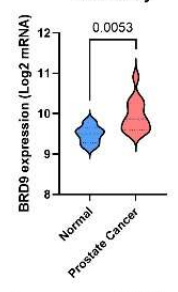

F TCGA

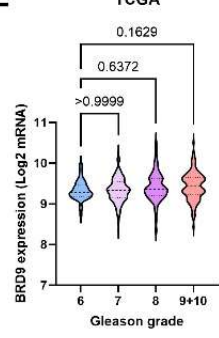

G

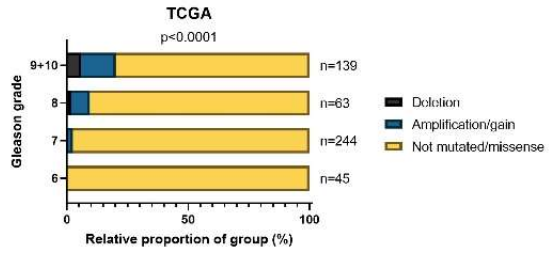

J varambally
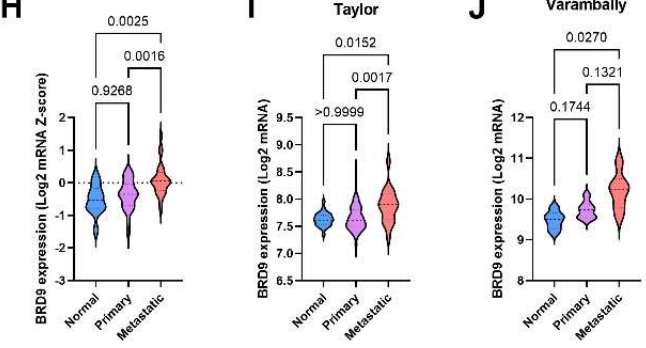

K

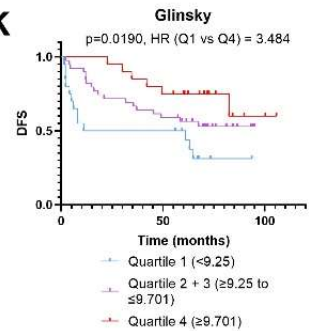

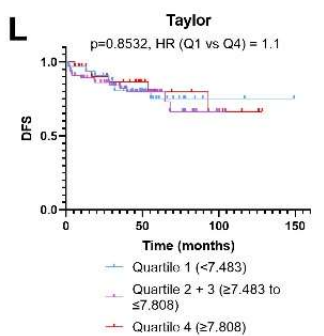

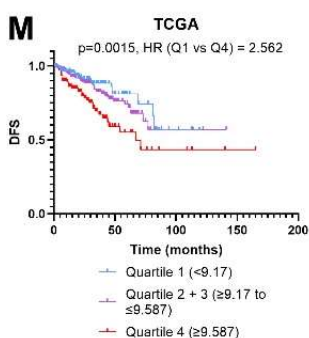

Figure 1: BRD9 as a diagnostic and prognostic biomarker in cancer omics cohorts.

(A) Violin plot showing BRD9 expression in normal and PCa patients in the Grasso cohort. P-value was obtained using Welch's t-test. (B) Violin plot showing BRD9 expression in normal and PCa patients in the Taylor cohort. P-value was obtained using Mann-Whitney U test. (C) Violin plot showing BRD9 expression in normal and PCa patients in the Varambally cohort. P-value was obtained using Welch's t-test. (D) Violin plot showing how BRD9 expression varies with Gleason grade in the Glinsky cohort. P-values were obtained using Dunnett's T3 post-hoc test. (E) Violin plot showing how BRD9 expression varies with Gleason grade in the Taylor cohort. P-values were obtained using Dunn's post-hoc test. (F) Violin plot showing how BRD9 expression varies with Gleason grade in the TCGA cohort. P-values were obtained using Dunnett's T3 post-hoc test. (G) Stacked bar chart showing BRD9 mutation distribution at different Gleason grades and the number of patients at each grade in the TCGA cohort $P$-value was obtained via Fisher's exact test using the Monte Carlo simulation. Grades 9 and 10 have been combined due to an $n=4$ sample size at grade 10. (H) Violin plot showing how BRD9 expression varies with cancer progression in the Grasso cohort. P-values were obtained using Dunn's post-hoc test. (I) Violin plot showing how BRD9 expression varies with cancer progression in the Taylor cohort. P-values were obtained using Dunn's post-hoc test. $(\boldsymbol{J})$ Violin plot showing how BRD9 expression varies with cancer progression in the Varambally cohort. P-values were obtained using Dunnett's T3 post-hoc test. (K) DFS shown via KM survival curve in the Glinsky cohort. P value was obtained from a Mantel-Cox test and HR was calculated from a cox regression model by comparing the highest and lowest quartiles of BRD9 expression. (L) DFS shown via KM survival curve in the Taylor cohort. $P$ value was obtained from a Mantel-Cox test and HR was calculated from a cox regression model by comparing the highest and lowest quartiles of BRD9 expression. (M) DFS shown via KM survival curve in the TCGA cohort. P value was obtained from a Mantel-Cox test and HR was calculated from a cox regression model by comparing the highest and lowest quartiles of BRD9 expression. Gleason grade (1-5) increases with more aggressive and less well-differentiated cancer. Overall grade (6-10) is the sum score of the two most prevalent grades in the sample. $Y$ axis scales on violin plots vary due to experimental variation.

\section{BRD9 is not overexpressed in patients with advanced stage PCa.}

BRD9 expression in advanced stage PCa was assessed. In all cohorts investigated, there was no significant change in BRD9 expression in more advanced stage disease

$(\alpha=0.05)($ Supplementary figure 1a,c,e-g). In the TCGA cohort, BRD9 mutations were more 
prevalent in patients with more advanced disease $(\mathrm{p}<0.0001)$ (Supplementary figure 1b), however this did not appear to be the case in the Ren cohort $(p=0.7062)$ (Supplementary figure 1d).

\section{BRD9 does not appear to play a role as a predictive biomarker in PCa.}

BRD9 expression levels were assessed in patient responses to therapy and in patients undergoing various therapeutic regimens. Data regarding this was lacking in most cohorts. There was no significant difference in BRD9 expression between primary therapy outcomes in the TCGA cohort $(\alpha=0.05)$ (Figure 2a). BRD9 mutations were less prevalent in patients with a complete response to primary therapy in this cohort $(\mathrm{p}<0.0001)($ Figure $2 \mathbf{b})$. There was no significant difference in BRD9 expression in patients indicated for adjuvant radiotherapy in the TCGA cohort ( $\mathrm{p}=0.4795)$ (Figure 2c), though BRD9 mutations were more prevalent in patients indicated for adjuvant radiotherapy here $(p<0.0001)$ (Figure 2d). There was no significant difference in BRD9 expression in patients who received chemotherapy in the Kumar cohort ( $\mathrm{p}=0.4564)$ (Figure 2e), though BRD9 mutations were more prevalent in patients who did not receive chemotherapy $(\mathrm{p}<0.0001)$ (Figure $2 \mathbf{f})$. There was no significant difference in BRD9 expression between different therapy regimens in the Abida cohort $(\alpha=0.05)$ (Figure 2g). BRD9 mutations appeared to be similarly prevalent across various regimens $(\mathrm{p}<0.0001)($ Figure $2 \mathbf{h})$. 
A

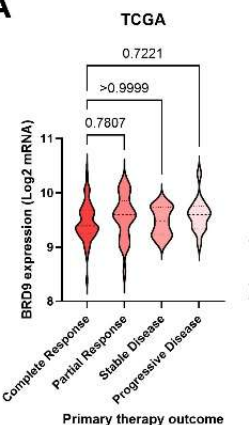

B

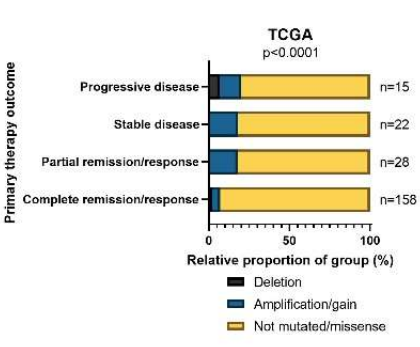

C

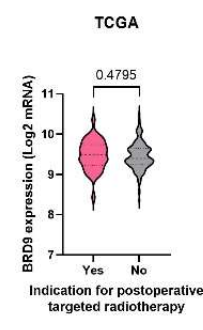

D

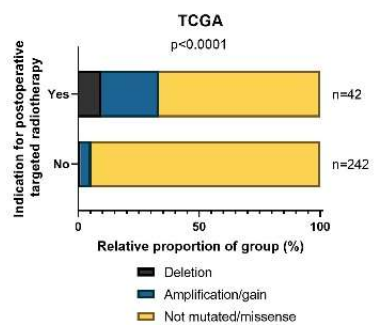

E

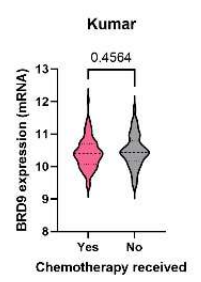

F

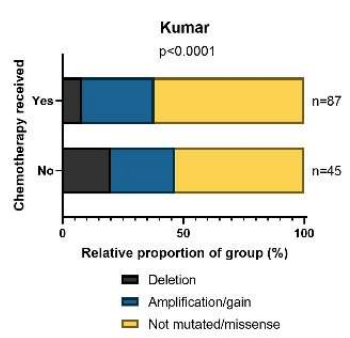

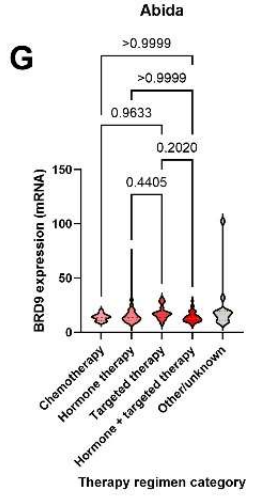

H

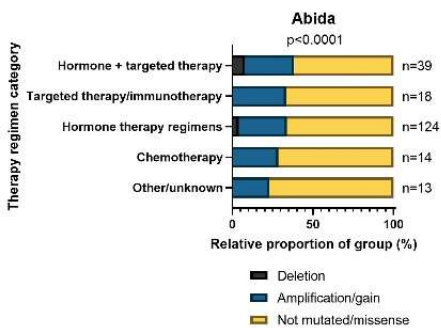

Figure 2: BRD9 as a predictive biomarker in PCa in cancer omics cohorts.

(A) Violin plot showing how BRD9 expression varies with primary therapy outcome in the TCGA cohort. P-values were obtained using Dunn's posthoc test. (B) Stacked bar chart showing BRD9 mutation distribution across primary therapy outcomes and the number of patients in each sample in the TCGA cohort. P-value was obtained via Fisher's exact test using the Monte Carlo simulation. (C) Violin plot showing BRD9 expression in patients indicated for adjuvant radiotherapy (left) and those who were not (right) in the TCGA cohort. P-value was obtained using a Mann Whitney $U$ test. (D) Stacked bar chart showing BRD9 mutation distribution in patients who were and were not indicated for adjuvant radiotherapy and the number of patients in each sample in the TCGA cohort. P-value was obtained using Fisher's exact test. (E) Violin plot showing BRD9 expression in patients who received chemotherapy (left) and those who did not (right) in the Kumar cohort. P-value was obtained using a Mann Whitney $U$ test. (F) Stacked bar chart showing BRD9 mutation distribution in patients who did and did not receive chemotherapy and the number of patients in each sample in the Kumar cohort. P-value was obtained via Fisher's exact test using the Monte Carlo simulation. (G) Violin plot showing how BRD9 expression varies with therapy regimen in the Abdia cohort. P-values were obtained using Dunn's post-hoc test. (H) Stacked bar chart showing BRD9 mutation distribution in patients across therapy regimens the number of patients in each sample in the TCGA cohort. P-value was obtained using Fisher's exact test. Regimen categories were combined as above due to small sample sizes $(n)$ of various individual regimens. $Y$ axis scales on violin plots vary due to experimental variation.

\section{It is unclear whether BRD9 could play a role as a therapeutic target in CRPC.}

BRD9 and AR mRNA expression correlation and BRD9 expression in patients receiving second generation antiandrogens (abiraterone and enzalutamide) was investigated. The TCGA cohort demonstrated a moderate negative correlation between BRD9 and AR expression in PCa patients ( $\mathrm{R}=-0.4117, \mathrm{p}<0.0001)$ (Figure 3a). There was no significant difference in BRD9 expression and abiraterone and enzalutamide exposure status in the Abida and Dan cohorts $(\alpha=0.05)$ (Figure 3b,d), however BRD9 mutations were more prevalent in patients treated with these drugs $(\mathrm{p}<0.0001)$ (Figure 3c,e) 

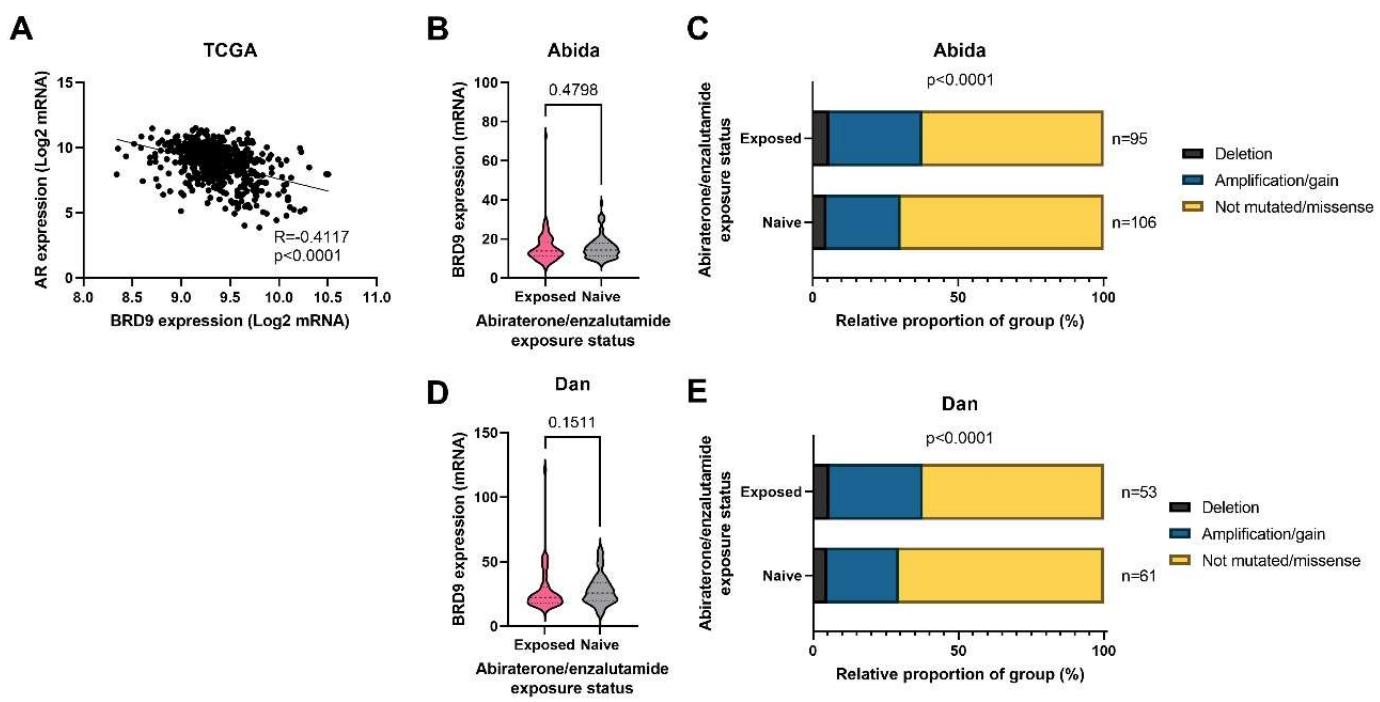

Figure 3: BRD9 as a potential drug target in CRPC in cancer omics cohorts.

(A) Scatterplot with line of best fit showing the correlation between BRD9 and AR expression in the TCGA cohort. Spearman's R and its associated two-tailed p-value have been calculated. (B) Violin plot showing BRD9 expression in who patients were and were not treated with the second generation antiandrogens abiraterone and enzalutamide in the Abida cohort. P-value was obtained using a Mann Whitney U test. (C) Stacked bar chart showing BRD9 mutation distribution in patients who were and were not treated with the second generation antiandrogens abiraterone and enzalutamide and the number of patients in each sample in the Abida cohort. P-value was obtained using Fisher's exact test. (D) Violin plot showing BRD9 expression in who patients were and were not treated with the second generation antiandrogens abiraterone and enzalutamide in the Dan cohort. P-value was obtained using a Mann Whitney $U$ test. (E) Stacked bar chart showing BRD9 mutation distribution in patients who were and were not treated with the second generation antiandrogens abiraterone and enzalutamide and the number of patients in each sample in the Dan cohort. P-value was obtained using Fisher's exact test. Y axis scales on violin plots vary due to experimental variation.

\section{BRD9 correlates with genes in the SWI/SNF and BET complexes.}

BRD9 expression and its correlation with other genes in the SWI/SNF and BET complexes was investigated. BRD9 expression was positively correlated with most genes in the SWI/SNF complex (Figure 4a-c): It was negatively correlated with ACTB, BCL7A, BCL7B, BCL7C, SMARCA4, SMARCC2, SMARCD1, SMARCD2, SMARCD3, GLTSCR1, DPF1, DPF2, SMARCB1 and SMARCE1 and negatively correlated with SMARCA2 and ARID2 at a significant level $(\alpha=0.05)$. The cohorts disagreed on whether BRD9 expression was positively or negatively correlated with other genes in the SWI/SNF complex at a significant level $(\alpha=0.05)$ (Supplementary Figure 2a). BRD9 was co-expressed, co-localised and physically interacted with SMARCD1. It also physically interacted with SS18 and shared a domain with BRD7 and PBRM1. BRD9 genetically interacted with DPF2 and was coexpressed with SMARCC1, SMARCC2, BCL7B and BCL7C (Supplementary Figure 2b). BRD9 was positively correlated with most genes in the BET complex (Figure 4d): it positively correlated with BRD2, BRD3 and BRD4 at a significant level in the Grasso, Taylor and Varambally cohorts $(\alpha=0.05)$. BRD9 was negatively correlated with BRDT at a significant level in the Taylor cohort - though it was positively correlated with BRDT in the other cohorts, the correlation was not significant $(\alpha=0.05)$ (Supplementary Figure 3a). 
BRD9 has shared protein domains with genes found in the BET complex, physically interacted with BRD4 and was co-expressed with BRD2 (Supplementary Figure 3b).

A

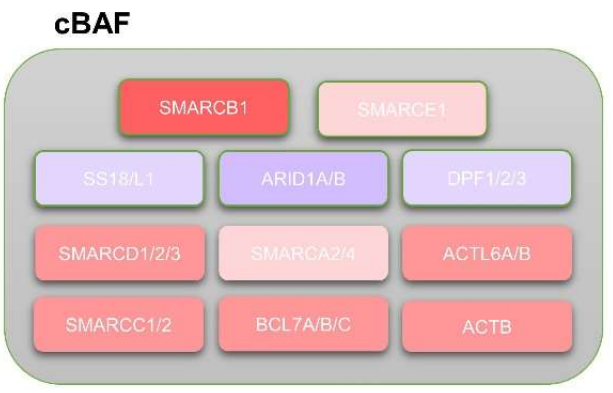

C
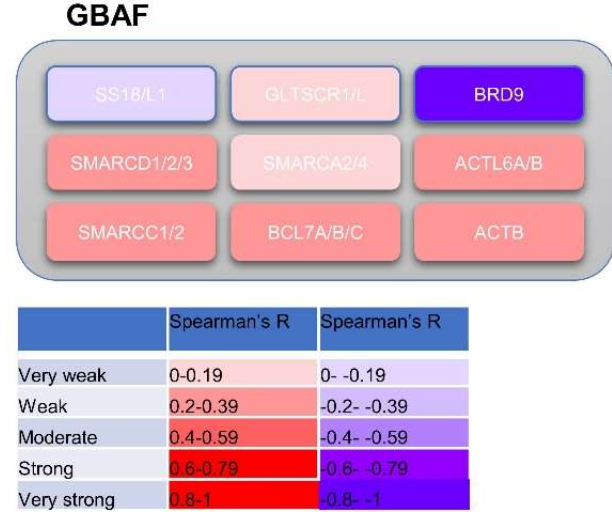

B PBAF

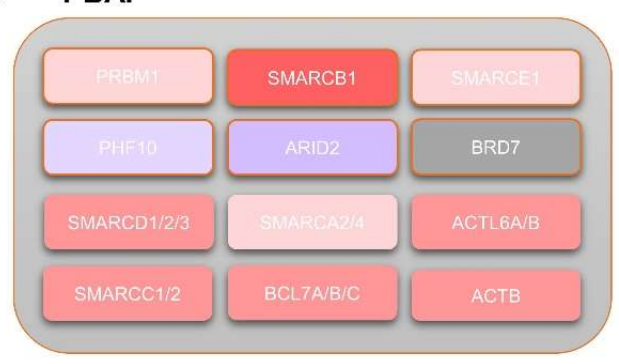

D BET complex

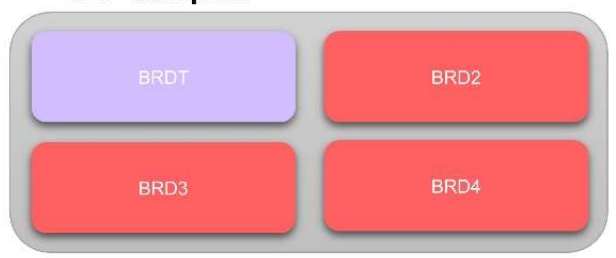

Figure 4: An overview of BRD9 correlation with genes composing the SWI/SNF and BET complexes. Heatmap diagrams showing mean significant Spearman's R BRD9 correlation from datasets with gene subunits composing SWI/SNF subcomplexes (CBAF, PBAF, GBAF) and BET complex. (A) Heatmap diagram showing mean significant Spearman's R BRD9 correlation from datasets with gene subunits composing the CBAF subcomplex. (B) Heatmap diagram showing mean significant Spearman's R BRD9 correlation from datasets with gene subunits composing the PBAF subcomplex. (C) Heatmap diagram showing mean significant Spearman's R BRD9 correlation from datasets with gene subunits composing the GBAF subcomplex. SWI/SNF diagrams adapted from Centore et al's Figure 1 [15]. Image created using Microsoft PowerPoint.

\section{BRD9 correlates with genes involved in common PCa proliferation-driving pathways}

The correlation of BRD9 with known genes involved in the JAK-STAT, MAPK and PI3KAKT-mTOR pathways was investigated (Figure 5). We found that BRD9 is negatively correlated with JAK2 and positively with TYK2. BRD9 was also positively correlated with STAT2, STAT4, STAT5A, STAT5B and STAT6 as well as PIM1, PIM2 and PIM3 at a significant level $(\alpha=0.05)$. The cohorts disagreed on its correlation with BCL2 and MYC; Taylor demonstrated a significant negative correlation between BRD9 and BCL2 however Varambally demonstrated the opposite $(\alpha=0.05)$. Taylor demonstrated a positive correlation between BRD9 and MYC whereas the Varambally cohort demonstrated the opposite. BRD9 was positively correlated with SOCS1 and negatively correlated with SOCS2, SOCS5 and SOCS6. It appeared to be positively correlated with SOCS3 and negatively correlated with SOCS4. The cohorts disagreed on whether it was positively or negatively correlated with SOCS7 - though Grasso and Varambally found significant positive correlations between 
BRD9 and SOCS7 expression, TCGA data showed a significant negative correlation between these genes $(\alpha=0.05)$ (Supplementary Figure 4a). BRD9 was co-expressed with TYK2, STAT4 and SOCS7 (Supplementary Figure 4b). In all cohorts investigated, there was a positive correlation between BRD9 expression and HRAS expression, though this was only significant in the Grasso, Taylor and TCGA cohorts $(\alpha=0.05)$. The cohorts disagreed on whether BRD9 is correlated with KRAS and NRAS positively or negatively at a significant level $(\alpha=0.05)$. BRD9 was positively correlated with ARAF, BRAF and RAF1 at a significant level in most of cohorts, however in the TCGA cohort the correlations are negative and significant $(\alpha=0.05)$. BRD9 was negatively correlated with MAP2K1 and positively correlated with MAP2K2. BRD9 was positively correlated with MAPK3 and negatively correlated with MAPK1 (Supplementary Figure 5a). BRD9 was co-expressed with HRAS, RAF1 and ARAF (Supplementary Figure 5b). BRD9 was negatively correlated with PIK3CA, PIK3CB, PIK3CG, PIK3R1, PIK3R3, PIK3R4, PIK3C2A, PIK3C2G and PIK3C3 $(\alpha=0.05)$. It was positively correlated with PIK3R2. BRD9 was negatively correlated with PTEN at a significant level in the Grasso, Taylor and TCGA cohorts $(\alpha=0.05)$. BRD9 was positively correlated with PDK1 at a significant level in the Grasso and Taylor cohorts $(\alpha=0.05)$. BRD9 was positively correlated with AKT1 and AKT2 however was negatively correlated with AKT3 $(\alpha=0.05)$. In terms of the TOR complexes, BRD9 was positively correlated with AKT1S1, RPTOR, MLST8, PRR5 and MAPKAP1 (Supplementary Figure 6a). BRD9 was co-expressed with PI3K3C2B and AKT2 (Supplementary Figure 6b). 


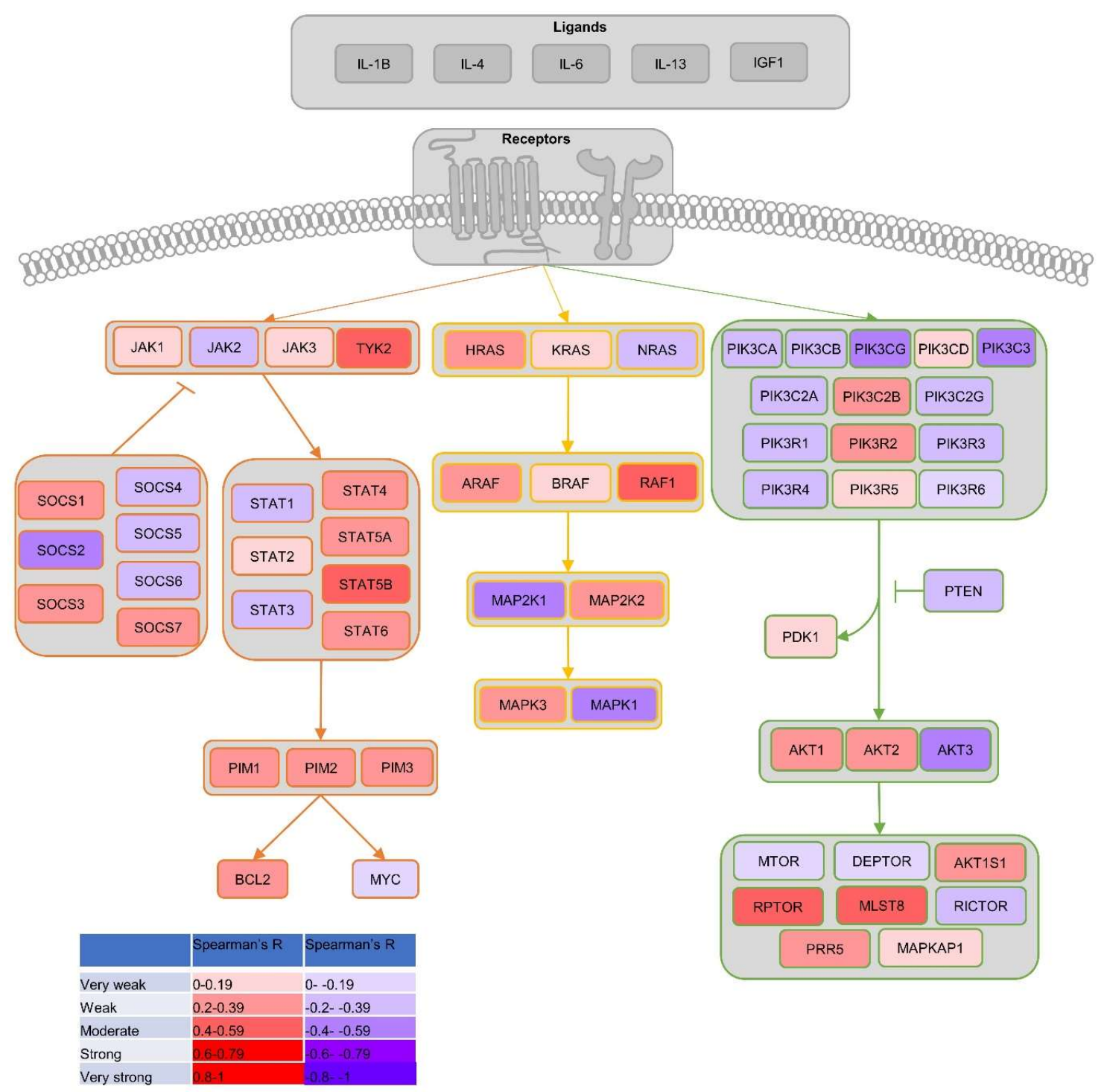

Figure 5: An overview of BRD9 correlation with common signalling pathways involved in PCa.

Flowchart signalling pathway diagram/heatmap showing mean significant Spearman's R BRD9 correlation from datasets with genes in the JAKSTAT, MAPK and PI3K-AKT-mTOR signalling pathways. Adapted and expanded from Luzczak et al's figure 2 [50]. Image created using Microsoft PowerPoint.

\section{BRD9 could play a role as a therapeutic co-target alongside ERG}

The potential BRD9 as a co-target with ERG was investigated. Though not directly related to ERG, BRD9 and ERG were indirectly connected via co-expression, physical and genetic interactions (Figure 6a). Prostate cancer is either ERG positive or negative; TMPRSS2 and ERG genes fuse increasing the expression of ERG in roughly half of cases. This is shown by the two distinct groups in the scatterplot, which also shows that BRD9 and ERG expression are positively correlated in the TCGA cohort (Figure 6b). BRD9 is overexpressed in ERG positive prostate cancer in the Barbieri $(\mathrm{p}=0.0024)$ and Gerhauser $(\mathrm{p}=0.0054)$ cohorts, however there was no significant difference in BRD9 expression in the Taylor $(p=0.1790)$ 
and Abida ( $\mathrm{p}=0.1304)$ cohorts (Figure 6c-f). BRD9 mutations were more prevalent in the ERG negative group in the Abida cohort $(\mathrm{p}<0.0001)($ Figure 6g).

A

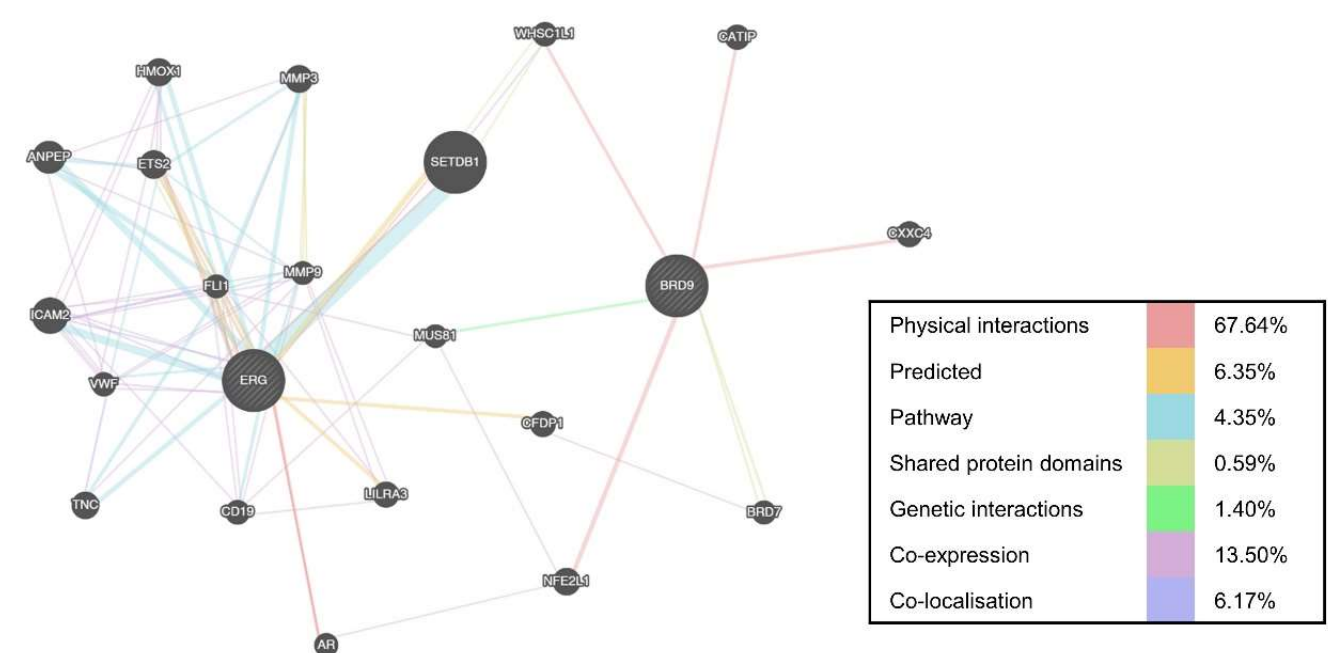

B

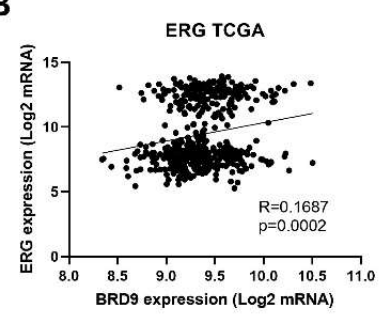

C

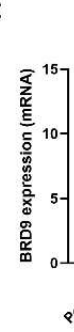

D

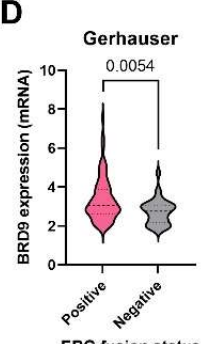

ERG fusion status

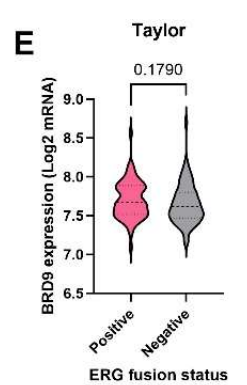

$\mathbf{F}$

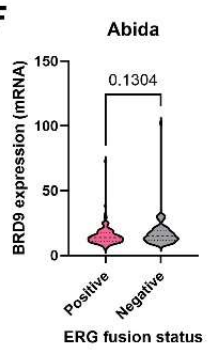

G

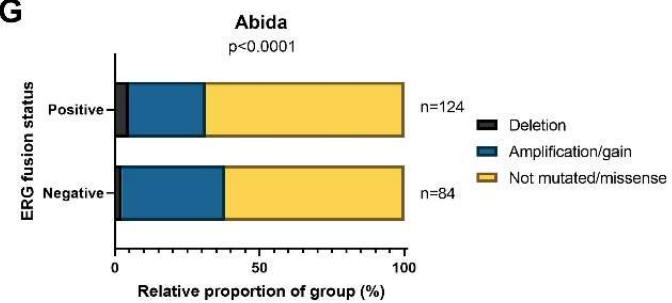

Figure 6: The potential of ERG as a co-target with BRD9.

(A) Gene network map showing the associations between BRD9 and ERG. (B) Scatterplot with line of best fit showing the correlation between BRD9 and ERG expression in the TCGA cohort. (C) Violin plot showing BRD9 expression in who patients were ERG (TMPRSS2-ETS fusion) positive (right) and negative (left) in the Barbieri cohort. P-value was obtained using a Mann Whitney U test. (D) Violin plot showing BRD9 expression in who patients were ERG positive (right) and negative (left) in the Gerhauser cohort. P-value was obtained using a Mann Whitney $U$ test. (E) Violin plot showing BRD9 expression in who patients were ERG positive (right) and negative (left) in the Taylor cohort. P-value was obtained using a Mann Whitney $U$ test. (F) Violin plot showing BRD9 expression in who patients were ERG positive (right) and negative (left) in the Abida cohort. P-value was obtained using a Mann Whitney U test. (G) Stacked bar chart showing BRD9 mutation distribution in patients who were ERG positive and negative and the number of patients in each sample in the Abida cohort. P-value was obtained using Fisher's exact test. $Y$ axis scales on violin plots vary due to experimental variation. Gene network map created using https://genemania.org/. 


\section{DISCUSSION}

Though BRD9 is understudied in PCa, growing interest in the community has recently pointed to a potential role in other cancers. Here, we set out to characterise BRD9 expression and mutations in depth within 11 independent PCa cohorts, to identify whether BRD9 has potential as a biomarker and therapeutic target or co-target in PCa.

\section{BRD9 as a biomarker}

SWI/SNF subunits are the most commonly mutated chromatin-regulatory complexes in human cancer, mutated in $19.6 \%$ cancers, with subunits ARID1A, PBRM1, SMARCA4, and ARID2 already part of routine cancer diagnostics [15,51]. The literature suggests BRD9 plays an oncogenic role in many cancers with promise both as a diagnostic and prognostic biomarker [52-54]. The only paper on BRD9 and PCa used the TCGA evidence to show BRD9 worsened DFS, however did not investigate BRD9 as a biomarker in PCa [30].

Our findings show BRD9 is overexpressed in PCa and therefore may play a role as a diagnostic biomarker in this disease. Currently, researchers are investigating panels of genes rather than individual genes in PCa diagnostics [55]. BRD9 could be a useful panel component given most genes composing a biomarker panel would not exhibit as strong correlations with disease status as BRD9 exhibits. Though BRD9 expression does not change with increases in Gleason grade and tumour stage, its expression was higher in metastatic PCa when compared to cancer-free patients and patients with local disease, suggesting BRD9 could play a role as a prognostic biomarker and therapeutic target, especially in metastatic PCa. As with any study of historic data, it should be noted that analysis methods have changed over time here. For Gleason scoring, both pathological methods and WHO classifications have changed during the collection of these data, which could affect the conclusions here, and is an unavoidable limitation in the use of publicly available retrospective cohorts. It has been shown that BRD9 is required for cell growth and its degradation prevents synovial sarcoma tumour progression [52,53]. Similar findings have been reported in hepatocellular carcinoma (HCC) with BRD9 overexpressed in HCC patients as well as promoting cell growth and metastasis, and its depletion and inhibition reducing these effects in HCC cells [54]. Data on DFS and BRD9 expression was conflicting, however the widely-studied TCGA cohort with the largest sample size found patients with higher 
BRD9 expression to have worse prognoses. Similarly, higher BRD9 expression reduces OS and DFS in HCC [54]. In the TCGA cohort, there is evidence suggesting BRD9 is more likely to be mutated in higher Gleason grades and more advanced cancer, screening these groups and targeting BRD9 in patients with mutations may be a viable therapeutic strategy. Though this data provides limited evidence that BRD9 plays a role as a predictive biomarker in $\mathrm{PCa}$, it suggests mutations are more prevalent in patients indicated for radiotherapy. Futher work should be carried out to determine if this means BRD9 expression correlates with some other factor that leads clinicians to indicate patients for radiotherapy. Targeting BRD9 may be synergistic with adjuvant radiotherapy, with one study finding BRD9 sensitised ovarian cancer cell lines to radiotherapy [56].

\section{BRD9 and CRPC}

Smith's paper on BRD9 in PCa suggests BRD9 could play a role in CRPC with BRD9 knockdown reducing the viability of AR-positive cell lines (including castration-resistant cell lines)[30]. Here, this cell line data was further characterised in $2053 \mathrm{PCa}$ patients and did not suggest as promising a role, given BRD9 expression was similar in patients treated with and without second-generation antiandrogens. However, decision to treat or not treat patients is made in the absence of knowledge of BRD9 expression, and a preferable experiment would be to compare BRD9 expression with response to antiandrogens in all patients - data which is not currently available within these datasets. While the cell line data is promising, cell lines cannot create a biomimetic environment, and are often contaminated or subject to genetic drift $[57,58,59]$. We look forward to clinical outcome data becoming available, allowing us to further investigate these findings in more relevant settings.

AR expression is moderately negatively correlated with AR expression in the TCGA cohort. Though this cohort was treatment-naïve, the correlation suggests that BRD9 could be a viable target in patients with AR-negative disease. After PCa differentiates into CRPC (stops responding to ADT) and is treated with second generation antiandrogens, it may stop responding to these also and then de-differentiate into AR-negative disease [60]. Though not in line with existing literature, if successful in AR-negative PCa, targeting BRD9 could be clinically very useful: following the introduction and approval of second-generation antiandrogens the percentage of patients with AR-negative tumours has increased from $11.7 \%$ (1996-2011) to 36.6\% (2012-16)[61]. Prognosis for AR-negative CRPC is poor with a 
median survival of 12 months for AR-negative small cell carcinoma [62]. A recent randomised-control trial found that the targeted PARPi Olaparib (recently FDA approved for PCa in May 2020) increased progression-free survival in patients with mCRPC whose cancer progressed despite abiraterone or enzalutamide treatment [63]. This suggests, like Olaparib, BRD9 may be a good therapeutic target in patients who stop responding to second generation antiandrogens. Another study found BRD9 depletion increased cancer cell chemotherapy sensitivity as well as sensitivity to Olaparib in Ovarian cancer, suggesting a drug targeting BRD9 may work synergistically with Olaparib [56].

\section{Co-targeting BRD9}

The literature suggests that suggest BRD9 interacts with other genes in the SWI/SNF complex and cooperates with BET proteins $[30,64]$.

We provide evidence showing that BRD9 correlates and associates with many genes in the SWI/SNF complex as well as most genes in the BET complex. BRD9 could therefore be a viable co-target alongside other genes in these complexes. Though their positive correlation is very weak, GLTSCR1 and its paralog GLTSCR1-like (GLTSCR1-L), the other unique GBAF complex components, interact with BRD9 [64]. Interestingly, BRD9 appears to be weakly positively correlated with SMARCB1 despite these genes being intrinsic competitors during SWI/SNF complex formation [65]. Alpsoy et al showed that BET complex and BRD9 inhibition exhibit similar effects and that BRD9 interacts with BRD2 and BRD4, with BRD9 and BET proteins, regulating similar gene sets [30]. Though the authors discussed the effects of targeting the GBAF subunit, they did not investigate other SWI/SNF subunits and BRD9's interactions with these.

The literature suggests that BRD9 may interact with genes in the JAK-STAT, MAPK and PI3K-AKT-mTor pathways. It has been shown that BRD9 depletion (at the mRNA and protein level) upregulates SOCS3 which in turn inhibits STAT5, reducing JAK-STAT pathway activation in acute myeloid leukaemia. Though BRD9 is not correlated with SOCS3 at a significant level in most cohorts and a weakly positive correlation overall, BRD9 and STAT5A/B mRNA expression are positively correlated [66]. BRD9 correlates with genes in the PI3K-AKT-mTOR pathway and associates with a few genes in this signaling cascade. Though there is no uniform BRD9-MYC correlation, one study found that BRD9 inhibition reduced MYC levels in breast epithelial cell lines [67]. It has also been shown that Mi-140-3p 
(a tumour-suppressive miRNA) targets BRD9 mRNA, downregulating MYC and reducing proliferation [68]. Interestingly BRD9 is negatively correlated with PIK3CA, its correlation with KRAS is non-uniform though it has been shown that BRD9 may mediate a PI3KCAKRAS mutant oncogenic cancer phenotype [67]. BRD9 positively correlates with most genes in the MAPK pathway with a few exceptions and has some associations with this signaling cascade. Given its correlations with genes in this pathway and trametinib being trialled here in PCa, BRD9 has most promise as a co-target with this pathway.

We provide some evidence (in two treatment naïve cohorts) that BRD9 is overexpressed in ERG fusion positive cancers and that ERG expression is very weakly correlated with BRD9 expression. This suggests BRD9 may be a worthwhile co-target alongside ERG. Our data shows BRD9 mutations are less prevalent in ERG fusion positive cancers, in line with the literature suggesting these cancers are less likely to have mutated SWI/SNF complexes $[69,70]$. BRD9 warrants further investigation in ERG fusion positive cancers and possibly cotargeted with ERG inhibition, as ERG depends on BAF complexes for its epithelial to mesenchymal transition (EMT) [71].

\section{Limitations}

This work investigated publicly available cohorts which have limitations including that not all cohorts had mutation data. Some cohorts had small sample sizes and most lacked data on patients with more advanced stage cancers. Most cohorts also did not include information on treatment response, meaning it is difficult conclude whether BRD9 has potential as a predictive biomarker using publicly available data. When comparing BRD9 expression in patients, available data, normal patients are not actually healthy patients, rather they have benign prostates. Some of the less recent data also uses grading classifications that we would not now e.g. Gleason Grade 5 is now not considered cancer.

In addition, it is not possible to determine causation - we can only study correlation in publicly available datasets; In future, overexpression, and knockdown studies must be performed to establish causation.

\section{CONCLUSION}


This approach to characterising BRD9 using cancer omics cohorts has yielded promising results and alongside the one published paper, forms a basis for future study of BRD9 in PCa. BRD9 has most potential as a diagnostic biomarker and drug target in metastatic disease. This work warrants further experimental work, in vitro, in vivo and ex vivo, to continue determining where and how targeting BRD9 could be successful in PCa. 


\section{REFERENCES}

1. Rawla, P. Epidemiology of Prostate Cancer. World J Oncol 2019, 10, 63-89, doi:10.14740/wjon1191.

2. Bray, F.; Ferlay, J.; Soerjomataram, I.; Siegel, R.L.; Torre, L.A.; Jemal, A. Global cancer statistics 2018: GLOBOCAN estimates of incidence and mortality worldwide for 36 cancers in 185 countries. CA Cancer J Clin 2018, 68, 394-424, doi:10.3322/caac.21492.

3. UK, P.C. About Prostate Cancer. Available online: https://prostatecanceruk.org/prostate-information/about-prostate-cancer (accessed on 19/04).

4. UK, P.C. Prostate Cancer UK's Best Practice Pathway TREATMENT; Prostate Cancer UK, 2019.

5. NICE. Information about PSA testing. Available online:

https://cks.nice.org.uk/topics/prostate-cancer/diagnosis/psa-

testing/\#: :text=If\%20the $\% 20$ prostate $\% 2$ Dspecific $\% 20$ antigen, $2 \% 20 \mathrm{weeks}$ ) $\% 20$ to $\%$ 20a\%20specialist (accessed on 19/04).

6. Ilic, D.; Djulbegovic, M.; Jung, J.H.; Hwang, E.C.; Zhou, Q.; Cleves, A.; Agoritsas, T.; Dahm, P. Prostate cancer screening with prostate-specific antigen (PSA) test: a systematic review and meta-analysis. Bmj 2018, 362, k3519, doi:10.1136/bmj.k3519.

7. Filella, X.; Fernández-Galan, E.; Fernández Bonifacio, R.; Foj, L. Emerging biomarkers in the diagnosis of prostate cancer. Pharmgenomics Pers Med 2018, 11, 83-94, doi:10.2147/pgpm.S136026.

8. Möller, A.; Olsson, H.; Grönberg, H.; Eklund, M.; Aly, M.; Nordström, T. The Stockholm3 blood-test predicts clinically-significant cancer on biopsy: independent validation in a multi-center community cohort. Prostate Cancer Prostatic Dis 2019, 22, 137-142, doi:10.1038/s41391-018-0082-5.

9. Grönberg, H. Stockholm3 Validation Study in a Multi-Ethnic Cohort (SEPTA). Available online: https://clinicaltrials.gov/ct2/show/NCT04583072 (accessed on 01/05).

10. Siow, Z.R.; De Boer, R.H.; Lindeman, G.J.; Mann, G.B. Spotlight on the utility of the Oncotype DX(®) breast cancer assay. Int J Womens Health 2018, 10, 89-100, doi:10.2147/ijwh.S124520. 
11. CRUK. Survival. Available online: https://www.cancerresearchuk.org/aboutcancer/prostate-cancer/survival (accessed on 20/04).

12. Fridriksson, J.; Folkvaljon, Y.; Nilsson, P.; Robinson, D.; Franck-Lissbrant, I.; Ehdaie, B.; Eastham, J.A.; Widmark, A.; Karlsson, C.T.; Stattin, P. Long-term adverse effects after curative radiotherapy and radical prostatectomy: populationbased nationwide register study. Scand J Urol 2016, 50, 338-345, doi:10.1080/21681805.2016.1194460.

13. Litwin, M.S.; Tan, H.J. The Diagnosis and Treatment of Prostate Cancer: A Review. Jama 2017, 317, 2532-2542, doi:10.1001/jama.2017.7248.

14. Staff, N. With Two FDA Approvals, Prostate Cancer Treatment Enters the PARP Era. 2020, 2021.

15. Centore, R.C.; Sandoval, G.J.; Soares, L.M.M.; Kadoch, C.; Chan, H.M. Mammalian SWI/SNF Chromatin Remodeling Complexes: Emerging Mechanisms and Therapeutic Strategies. Trends Genet 2020, 36, 936-950, doi:10.1016/j.tig.2020.07.011.

16. Shi, J.; Vakoc, C.R. The mechanisms behind the therapeutic activity of BET bromodomain inhibition. Mol Cell 2014, 54, 728-736, doi:10.1016/j.molcel.2014.05.016.

17. Wyce, A.; Degenhardt, Y.; Bai, Y.; Le, B.; Korenchuk, S.; Crouthame, M.C.; McHugh, C.F.; Vessella, R.; Creasy, C.L.; Tummino, P.J.; et al. Inhibition of BET bromodomain proteins as a therapeutic approach in prostate cancer. Oncotarget 2013, 4, 2419-2429, doi:10.18632/oncotarget.1572.

18. Canesin, G.; Krzyzanowska, A.; Hellsten, R.; Bjartell, A. Cytokines and Janus kinase/signal transducer and activator of transcription signaling in prostate cancer: overview and therapeutic opportunities. Current Opinion in Endocrine and Metabolic Research 2020, 10, 36-42, doi:https://doi.org/10.1016/j.coemr.2020.02.004.

19. Haddad, B.R.; Gu, L.; Mirtti, T.; Dagvadorj, A.; Vogiatzi, P.; Hoang, D.T.; Bajaj, R.; Leiby, B.; Ellsworth, E.; Blackmon, S.; et al. STAT5A/B gene locus undergoes amplification during human prostate cancer progression. Am J Pathol 2013, 182, 2264-2275, doi:10.1016/j.ajpath.2013.02.044.

20. Rodríguez-Berriguete, G.; Fraile, B.; Martínez-Onsurbe, P.; Olmedilla, G.; Paniagua, R.; Royuela, M. MAP Kinases and Prostate Cancer. J Signal Transduct 2012, 2012, 169170, doi:10.1155/2012/169170. 
21. Mukherjee, R.; McGuinness, D.H.; McCall, P.; Underwood, M.A.; Seywright, M.; Orange, C.; Edwards, J. Upregulation of MAPK pathway is associated with survival in castrate-resistant prostate cancer. Br J Cancer 2011, 104, 1920-1928, doi:10.1038/bjc.2011.163.

22. Center, J.C.C. Trametinib in Treating Patients With Progressive Metastatic HormoneResistant Prostate Cancer. Available online: https://clinicaltrials.gov/ct2/show/NCT02881242 (accessed on 01/05).

23. Edlind, M.P.; Hsieh, A.C. PI3K-AKT-mTOR signaling in prostate cancer progression and androgen deprivation therapy resistance. Asian J Androl 2014, 16, 378-386, doi:10.4103/1008-682x.122876.

24. de Bono, J.S.; De Giorgi, U.; Rodrigues, D.N.; Massard, C.; Bracarda, S.; Font, A.; Arranz Arija, J.A.; Shih, K.C.; Radavoi, G.D.; Xu, N.; et al. Randomized Phase II Study Evaluating Akt Blockade with Ipatasertib, in Combination with Abiraterone, in Patients with Metastatic Prostate Cancer with and without PTEN Loss. Clin Cancer Res 2019, 25, 928-936, doi:10.1158/1078-0432.Ccr-18-0981.

25. Roche, H.-L. Ipatasertib Plus Abiraterone Plus Prednisone/Prednisolone, Relative to Placebo Plus Abiraterone Plus Prednisone/Prednisolone in Adult Male Patients With Metastatic Castrate-Resistant Prostate Cancer (IPATential150). Available online: https://clinicaltrials.gov/ct2/show/study/NCT03072238 (accessed on 01/05).

26. Bono, J.D. ESMO Virtual Congress 2020: IPATential150: Phase III Study of Ipatasertib plus Abiraterone vs Placebo plus Abiraterone in Metastatic CastrationResistant Prostate Cancer. In Proceedings of the ESMO Virtual Congress, 2020.

27. Tomlins, S.A.; Laxman, B.; Varambally, S.; Cao, X.; Yu, J.; Helgeson, B.E.; Cao, Q.; Prensner, J.R.; Rubin, M.A.; Shah, R.B.; et al. Role of the TMPRSS2-ERG gene fusion in prostate cancer. Neoplasia 2008, 10, 177-188, doi:10.1593/neo.07822.

28. Demichelis, F.; Fall, K.; Perner, S.; Andrén, O.; Schmidt, F.; Setlur, S.R.; Hoshida, Y.; Mosquera, J.M.; Pawitan, Y.; Lee, C.; et al. TMPRSS2:ERG gene fusion associated with lethal prostate cancer in a watchful waiting cohort. Oncogene 2007, 26, 4596-4599, doi:10.1038/sj.onc.1210237.

29. Mohamed, A.A.; Xavier, C.P.; Sukumar, G.; Tan, S.H.; Ravindranath, L.; Seraj, N.; Kumar, V.; Sreenath, T.; McLeod, D.G.; Petrovics, G.; et al. Identification of a Small Molecule That Selectively Inhibits ERG-Positive Cancer Cell Growth. Cancer Res 2018, 78, 3659-3671, doi:10.1158/0008-5472.Can-17-2949. 
30. Alpsoy, A.; Utturkar, S.M.; Carter, B.C.; Dhiman, A.; Torregrosa-Allen, S.E.; Currie, M.P.; Elzey, B.D.; Dykhuizen, E.C. BRD9 Is a Critical Regulator of Androgen Receptor Signaling and Prostate Cancer Progression. Cancer Research 2021, 81, 820833, doi:10.1158/0008-5472.Can-20-1417.

31. Kirby, M.; Hirst, C.; Crawford, E.D. Characterising the castration-resistant prostate cancer population: a systematic review. Int J Clin Pract 2011, 65, 1180-1192, doi:10.1111/j.1742-1241.2011.02799.x.

32. Cortazar, A.R.; Torrano, V.; Martín-Martín, N.; Caro-Maldonado, A.; Camacho, L.; Hermanova, I.; Guruceaga, E.; Lorenzo-Martín, L.F.; Caloto, R.; Gomis, R.R.; et al. CANCERTOOL: A Visualization and Representation Interface to Exploit Cancer Datasets. Cancer Res 2018, 78, 6320-6328, doi:10.1158/0008-5472.Can-18-1669.

33. Cerami, E.; Gao, J.; Dogrusoz, U.; Gross, B.E.; Sumer, S.O.; Aksoy, B.A.; Jacobsen, A.; Byrne, C.J.; Heuer, M.L.; Larsson, E.; et al. The cBio cancer genomics portal: an open platform for exploring multidimensional cancer genomics data. Cancer Discov 2012, 2, 401-404, doi:10.1158/2159-8290.Cd-12-0095.

34. Gao, J.; Aksoy, B.A.; Dogrusoz, U.; Dresdner, G.; Gross, B.; Sumer, S.O.; Sun, Y.; Jacobsen, A.; Sinha, R.; Larsson, E.; et al. Integrative analysis of complex cancer genomics and clinical profiles using the cBioPortal. Sci Signal 2013, 6, pl1, doi:10.1126/scisignal.2004088.

35. Warde-Farley, D.; Donaldson, S.L.; Comes, O.; Zuberi, K.; Badrawi, R.; Chao, P.; Franz, M.; Grouios, C.; Kazi, F.; Lopes, C.T.; et al. The GeneMANIA prediction server: biological network integration for gene prioritization and predicting gene function. Nucleic Acids Res 2010, 38, W214-220, doi:10.1093/nar/gkq537.

36. The Molecular Taxonomy of Primary Prostate Cancer. Cell 2015, 163, 1011-1025, doi:10.1016/j.cell.2015.10.025.

37. Glinsky, G.V.; Glinskii, A.B.; Stephenson, A.J.; Hoffman, R.M.; Gerald, W.L. Gene expression profiling predicts clinical outcome of prostate cancer. J Clin Invest 2004, 113, 913-923, doi:10.1172/jci20032.

38. Grasso, C.S.; Wu, Y.M.; Robinson, D.R.; Cao, X.; Dhanasekaran, S.M.; Khan, A.P.; Quist, M.J.; Jing, X.; Lonigro, R.J.; Brenner, J.C.; et al. The mutational landscape of lethal castration-resistant prostate cancer. Nature 2012, 487, 239-243, doi:10.1038/nature11125. 
39. Taylor, B.S.; Schultz, N.; Hieronymus, H.; Gopalan, A.; Xiao, Y.; Carver, B.S.; Arora, V.K.; Kaushik, P.; Cerami, E.; Reva, B.; et al. Integrative genomic profiling of human prostate cancer. Cancer Cell 2010, 18, 11-22, doi:10.1016/j.ccr.2010.05.026.

40. Varambally, S.; Yu, J.; Laxman, B.; Rhodes, D.R.; Mehra, R.; Tomlins, S.A.; Shah, R.B.; Chandran, U.; Monzon, F.A.; Becich, M.J.; et al. Integrative genomic and proteomic analysis of prostate cancer reveals signatures of metastatic progression. Cancer Cell 2005, 8, 393-406, doi:10.1016/j.ccr.2005.10.001.

41. Gerhauser, C.; Favero, F.; Risch, T.; Simon, R.; Feuerbach, L.; Assenov, Y.; Heckmann, D.; Sidiropoulos, N.; Waszak, S.M.; Hübschmann, D.; et al. Molecular Evolution of Early-Onset Prostate Cancer Identifies Molecular Risk Markers and Clinical Trajectories. Cancer Cell 2018, 34, 996-1011.e1018, doi:10.1016/j.ccell.2018.10.016.

42. Barbieri, C.E.; Baca, S.C.; Lawrence, M.S.; Demichelis, F.; Blattner, M.; Theurillat, J.P.; White, T.A.; Stojanov, P.; Van Allen, E.; Stransky, N.; et al. Exome sequencing identifies recurrent SPOP, FOXA1 and MED12 mutations in prostate cancer. Nat Genet 2012, 44, 685-689, doi:10.1038/ng.2279.

43. Ren, S.; Wei, G.-H.; Liu, D.; Wang, L.; Hou, Y.; Zhu, S.; Peng, L.; Zhang, Q.; Cheng, Y.; Su, H.; et al. Whole-genome and Transcriptome Sequencing of Prostate Cancer Identify New Genetic Alterations Driving Disease Progression. European Urology 2018, 73, 322-339, doi:https://doi.org/10.1016/j.eururo.2017.08.027.

44. Abida, W.; Cyrta, J.; Heller, G.; Prandi, D.; Armenia, J.; Coleman, I.; Cieslik, M.; Benelli, M.; Robinson, D.; Van Allen, E.M.; et al. Genomic correlates of clinical outcome in advanced prostate cancer. Proc Natl Acad Sci U S A 2019, 116, 1142811436, doi:10.1073/pnas.1902651116.

45. Dan, R.; Van Allen, E.M.; Wu, Y.M.; Schultz, N.; Lonigro, R.J.; Mosquera, J.M.; Montgomery, B.; Taplin, M.E.; Pritchard, C.C.; Attard, G.; et al. Integrative clinical genomics of advanced prostate cancer. Cell 2015, 161, 1215-1228, doi:10.1016/j.cell.2015.05.001.

46. Kumar, A.; Coleman, I.; Morrissey, C.; Zhang, X.; True, L.D.; Gulati, R.; Etzioni, R.; Bolouri, H.; Montgomery, B.; White, T.; et al. Substantial interindividual and limited intraindividual genomic diversity among tumors from men with metastatic prostate cancer. Nature Medicine 2016, 22, 369-378, doi:10.1038/nm.4053.

47. Morpheus. 
48. Weissgerber, T.L.; Winham, S.J.; Heinzen, E.P.; Milin-Lazovic, J.S.; GarciaValencia, O.; Bukumiric, Z.; Savic, M.D.; Garovic, V.D.; Milic, N.M. Reveal, Don't Conceal: Transforming Data Visualization to Improve Transparency. Circulation 2019, 140, 1506-1518, doi:10.1161/circulationaha.118.037777.

49. BMJ. Correlation and Regression. Available online: https://www.bmj.com/aboutbmj/resources-readers/publications/statistics-square-one/11-correlation-andregression (accessed on 23/04).

50. Luszczak, S.; Kumar, C.; Sathyadevan, V.K.; Simpson, B.S.; Gately, K.A.; Whitaker, H.C.; Heavey, S. PIM kinase inhibition: co-targeted therapeutic approaches in prostate cancer. Signal Transduct Target Ther 2020, 5, 7, doi:10.1038/s41392-0200109-y.

51. Kadoch, C.; Hargreaves, D.C.; Hodges, C.; Elias, L.; Ho, L.; Ranish, J.; Crabtree, G.R. Proteomic and bioinformatic analysis of mammalian SWI/SNF complexes identifies extensive roles in human malignancy. Nat Genet 2013, 45, 592-601, doi:10.1038/ng.2628.

52. Zhu, X.; Liao, Y.; Tang, L. Targeting BRD9 for Cancer Treatment: A New Strategy. Onco Targets Ther 2020, 13, 13191-13200, doi:10.2147/ott.S286867.

53. Brien, G.L.; Remillard, D.; Shi, J.; Hemming, M.L.; Chabon, J.; Wynne, K.; Dillon, E.T.; Cagney, G.; Van Mierlo, G.; Baltissen, M.P.; et al. Targeted degradation of BRD9 reverses oncogenic gene expression in synovial sarcoma. Elife 2018, 7, doi:10.7554/eLife.41305.

54. Dou, C.; Sun, L.; Wang, L.; Cheng, J.; Wu, W.; Zhang, C.; Xu, Q.; Tu, K.; Liu, J. Bromodomain-containing protein 9 promotes the growth and metastasis of human hepatocellular carcinoma by activating the TUFT1/AKT pathway. Cell Death \& Disease 2020, 11, 730, doi:10.1038/s41419-020-02943-7.

55. Guo, J.; Yang, J.; Zhang, X.; Feng, X.; Zhang, H.; Chen, L.; Johnson, H.; Persson, J.L.; Xiao, K. A Panel of Biomarkers for Diagnosis of Prostate Cancer Using Urine Samples. Anticancer Res 2018, 38, 1471-1477, doi:10.21873/anticanres.12373.

56. Zhou, Q.; Huang, J.; Zhang, C.; Zhao, F.; Kim, W.; Tu, X.; Zhang, Y.; Nowsheen, S.; Zhu, Q.; Deng, M.; et al. The bromodomain containing protein BRD-9 orchestrates RAD51-RAD54 complex formation and regulates homologous recombinationmediated repair. Nature Communications 2020, 11, 2639, doi:10.1038/s41467-02016443-x.

57. Ghallab, A. In vitro test systems and their limitations. Excli j 2013, 12, 1024-1026. 
58. Geraghty, R.J.; Capes-Davis, A.; Davis, J.M.; Downward, J.; Freshney, R.I.; Knezevic, I.; Lovell-Badge, R.; Masters, J.R.W.; Meredith, J.; Stacey, G.N.; et al. Guidelines for the use of cell lines in biomedical research. British Journal of Cancer 2014, 111, 1021-1046, doi:10.1038/bjc.2014.166.

59. Olarerin-George, A.O.; Hogenesch, J.B. Assessing the prevalence of mycoplasma contamination in cell culture via a survey of NCBI's RNA-seq archive. Nucleic Acids Res 2015, 43, 2535-2542, doi:10.1093/nar/gkv136.

60. Formaggio, N.; Rubin, M.A.; Theurillat, J.-P. Loss and revival of androgen receptor signaling in advanced prostate cancer. Oncogene 2021, 40, 1205-1216, doi:10.1038/s41388-020-01598-0.

61. Bluemn, E.G.; Coleman, I.M.; Lucas, J.M.; Coleman, R.T.; Hernandez-Lopez, S.; Tharakan, R.; Bianchi-Frias, D.; Dumpit, R.F.; Kaipainen, A.; Corella, A.N.; et al. Androgen Receptor Pathway-Independent Prostate Cancer Is Sustained through FGF Signaling. Cancer Cell 2017, 32, 474-489.e476, doi:10.1016/j.ccell.2017.09.003.

62. Metzger, A.L.; Abel, S.; Wegner, R.E.; Fuhrer, R.; Mao, S.; Miller, R.; Beriwal, S.; Horne, Z.D. Patterns of care and outcomes in small cell carcinoma of the prostate: A national cancer database analysis. Prostate 2019, 79, 1457-1461, doi:10.1002/pros.23864.

63. de Bono, J.; Mateo, J.; Fizazi, K.; Saad, F.; Shore, N.; Sandhu, S.; Chi, K.N.; Sartor, O.; Agarwal, N.; Olmos, D.; et al. Olaparib for Metastatic Castration-Resistant Prostate Cancer. N Engl J Med 2020, 382, 2091-2102, doi:10.1056/NEJMoa1911440.

64. Gatchalian, J.; Malik, S.; Ho, J.; Lee, D.S.; Kelso, T.W.R.; Shokhirev, M.N.; Dixon, J.R.; Hargreaves, D.C. A non-canonical BRD9-containing BAF chromatin remodeling complex regulates naive pluripotency in mouse embryonic stem cells. Nat Commun 2018, 9, 5139, doi:10.1038/s41467-018-07528-9.

65. Wang, X.; Wang, S.; Troisi, E.C.; Howard, T.P.; Haswell, J.R.; Wolf, B.K.; Hawk, W.H.; Ramos, P.; Oberlick, E.M.; Tzvetkov, E.P.; et al. BRD9 defines a SWI/SNF sub-complex and constitutes a specific vulnerability in malignant rhabdoid tumors. Nat Commun 2019, 10, 1881, doi:10.1038/s41467-019-09891-7.

66. Del Gaudio, N.; Di Costanzo, A.; Liu, N.Q.; Conte, L.; Migliaccio, A.; Vermeulen, M.; Martens, J.H.A.; Stunnenberg, H.G.; Nebbioso, A.; Altucci, L. BRD9 binds cell type-specific chromatin regions regulating leukemic cell survival via STAT5 inhibition. Cell Death \& Disease 2019, 10, 338, doi:10.1038/s41419-019-1570-9. 
67. Bell, C.M.; Raffeiner, P.; Hart, J.R.; Vogt, P.K. PIK3CA Cooperates with KRAS to Promote MYC Activity and Tumorigenesis via the Bromodomain Protein BRD9. Cancers (Basel) 2019, 11, doi:10.3390/cancers11111634.

68. Huang, H.; Wang, Y.; Li, Q.; Fei, X.; Ma, H.; Hu, R. miR-140-3p functions as a tumor suppressor in squamous cell lung cancer by regulating BRD9. Cancer Letters 2019, 446, 81-89, doi:https://doi.org/10.1016/j.canlet.2019.01.007.

69. Hartley, A.; Leung, H.Y.; Ahmad, I. Targeting the BAF complex in advanced prostate cancer. Expert Opinion on Drug Discovery 2021, 16, 173-181, doi:10.1080/17460441.2020.1821644.

70. Armenia, J.; Wankowicz, S.A.M.; Liu, D.; Gao, J.; Kundra, R.; Reznik, E.; Chatila, W.K.; Chakravarty, D.; Han, G.C.; Coleman, I.; et al. The long tail of oncogenic drivers in prostate cancer. Nat Genet 2018, 50, 645-651, doi:10.1038/s41588-0180078-z.

71. Sandoval, G.J.; Pulice, J.L.; Pakula, H.; Schenone, M.; Takeda, D.Y.; Pop, M.; Boulay, G.; Williamson, K.E.; McBride, M.J.; Pan, J.; et al. Binding of TMPRSS2ERG to BAF Chromatin Remodeling Complexes Mediates Prostate Oncogenesis. Mol Cell 2018, 71, 554-566.e557, doi:10.1016/j.molcel.2018.06.040. 